\title{
Performance evaluation of released bread wheat varieties at mid altitude areas of Southern Ethiopia
}

\author{
Shibeshi S \\ Southern Agricultural Research Institution, Worabe Agricultural Research Center, Ethiopia \\ E-mail: shibeshisolomon23@gmail.com
}

Received: 05.12.2019. Accepted: 31.12.2019

\begin{abstract}
Bread wheat (Triticum aestivum L.) is the most important cereal occupying a protruding position among major food crops in the world in terms of acreage and production and is an important cereal crop which is receives the most attention of specialists in plant breeding and production in the world wide in general and in Ethiopia in particular. And also a number of improved bread wheat varieties have been released by different research centres for different agro-ecology in Ethiopia. Evaluate the performance of different bread wheat varieties at diverse agro-ecology is an important for effective selection of the variety. This experiment was conducted on ten bread wheat varieties against local check (Digalu) at Meskan and Dalocha wereda with the objective of identify and recommend high performance in terms of yield, insect pest tolerant, and stable varieties. The varieties were assigned in randomized complete block design with four replication. Data were collected on six major agronomic traits. Based on the mean separation, the highest average grain yield was recorded from Hidasse and Ogolcho varieties with 5210 and $5080 \mathrm{~kg} / \mathrm{ha}$ respectively. However the lowest average yield $(3220 \mathrm{~kg} / \mathrm{ha})$ was recorded from Digalu variety. In both locations Digalu variety provided the lowest yield due to high susceptibility for stem rust. Statistically, the variety Hidasse gave the highest number of tillers per plant and the tallest spikes length at both locations those are positive contributions to grain yield. There were significantly positive and negative correlations between traits. In this study, it is found that there is $38.19 \%$ increment of yield for using Hidasse variety (high yielder) as compared to Digalu variety (low yielder) at the study area. Therefore, farmers located at the study areas are recommended to use Hidasse variety to increase bread wheat yield.
\end{abstract}

Keywords: Bread wheat; Genotype; Germplasm; Grain yield

\section{Introduction}

Bread wheat (Triticum aestivum L.) is the world's leading cereal grain and more than one-third of the population of the world uses as a staple food (Obsa, 2014). Wheat is one of the major cereal crops grown in Ethiopia, and the country is endowed with a wealth of genetic diversity, particularly for tetraploid wheat (Hailu et al, 1991). It is the fourth largest cereal crop produced by close to 5 million smallholder farmers, which makes about 35 percent of all small farmers in the country (CSA, 2013). After South Africa, Ethiopia is the second largest wheat producer in sub-Saharan Africa (FAO, 2015). Bread wheat is a staple food in the diets of several Ethiopian, providing about 15 percent of the caloric intake for the country's over 90 million population (FAO, 2015).

Wheat is a self-pollinating annual plant in the true grass family Gramineae (Poaceae), is widely grown as staple food sources in the world, Mollasadeghi and Shahryari (2011). It is exclusively produced under rain fed conditions, meher and belg (long and short rainy seasons), respectively. The genetic origin of wheat is of interest; since it is a classic example of how closely related species may be combined in nature into a polyploid series. The species of Triticum (T.) and their close relatives can be divided into diploid, tetraploid and hexaploid groups, with chromosome numbers of $2 n=14,28$ and 42, respectively, in which the basic chromosome number of wheat is $x=7$. Triticum durum originated thousands of years ago from a hybridization between the wild diploid ( $T$. monococcum L). (A genome donor) and the donor of the B genome which, according to morphological, geographical and cytological evidence, has been recognized as T. speltoides (Tausch) Gren or a closely related species (Abu, 2012).

Wheat is grown at an altitude ranging from 1500 to 3000 m.a.s.l, between 6-160 N latitude and 35-420 E longitude in Ethiopia. The most suitable agro- ecological zones, however, fall between 1900 and 2700_m.a.s.l. (Abu, 2012). In Ethiopia, bread wheat improvement has started in 1949 and up to now many varieties have been released by the national and regional research institutes. However, those varieties are not widely distributed to all parts of the country. This is because of several constraints including the remoteness and in accessibilities of the growing areas that limited to test the adaptability and yields of the varieties in such areas. It is necessary to evaluate varieties for the intended growing regions since varieties were recommended as high yielding after evaluating at few representative wheat growing areas, in other words the varieties were not evaluated in all wheat growing regions. Nevertheless, the productivity of wheat has remained very low mainly because improved production technologies have not been adopted by the farming community. To change the status quo, therefore, it was felt necessary to conduct a multidisciplinary review of wheat research in Ethiopia (kifle Zerga et al 2017). At Gurage and Siliti zone of South Nation, Nationality region are one of the areas where improved varieties are not widely distributed so far, most probably due to the above indicated problems. Particularly, the potential of the area to wheat crop is not exploited due to lack of improved varieties. There is no detail information indicating the adaptability and production status of the improved bread wheat varieties in the area. Therefore, the objective of the study was to evaluate, select and recommend high yielder, tolerant to diseases, more adapted and stable bread wheat variety/ies in the study area. 


\section{Materials and Methods}

\section{Area description}

The experiment was carried out at Siliti zone Dalocha woreda (Figure 1);(average T0 12-22.5 C; Altitude 1900_m a.s.I) and Gurage zone Meskan Wordas (Figure 2); (average T0 11.8-25.5 ${ }^{\circ} \mathrm{C}$; Altitude 1800_m a.s.I) in 2015 and 2016 main cropping season for two years.

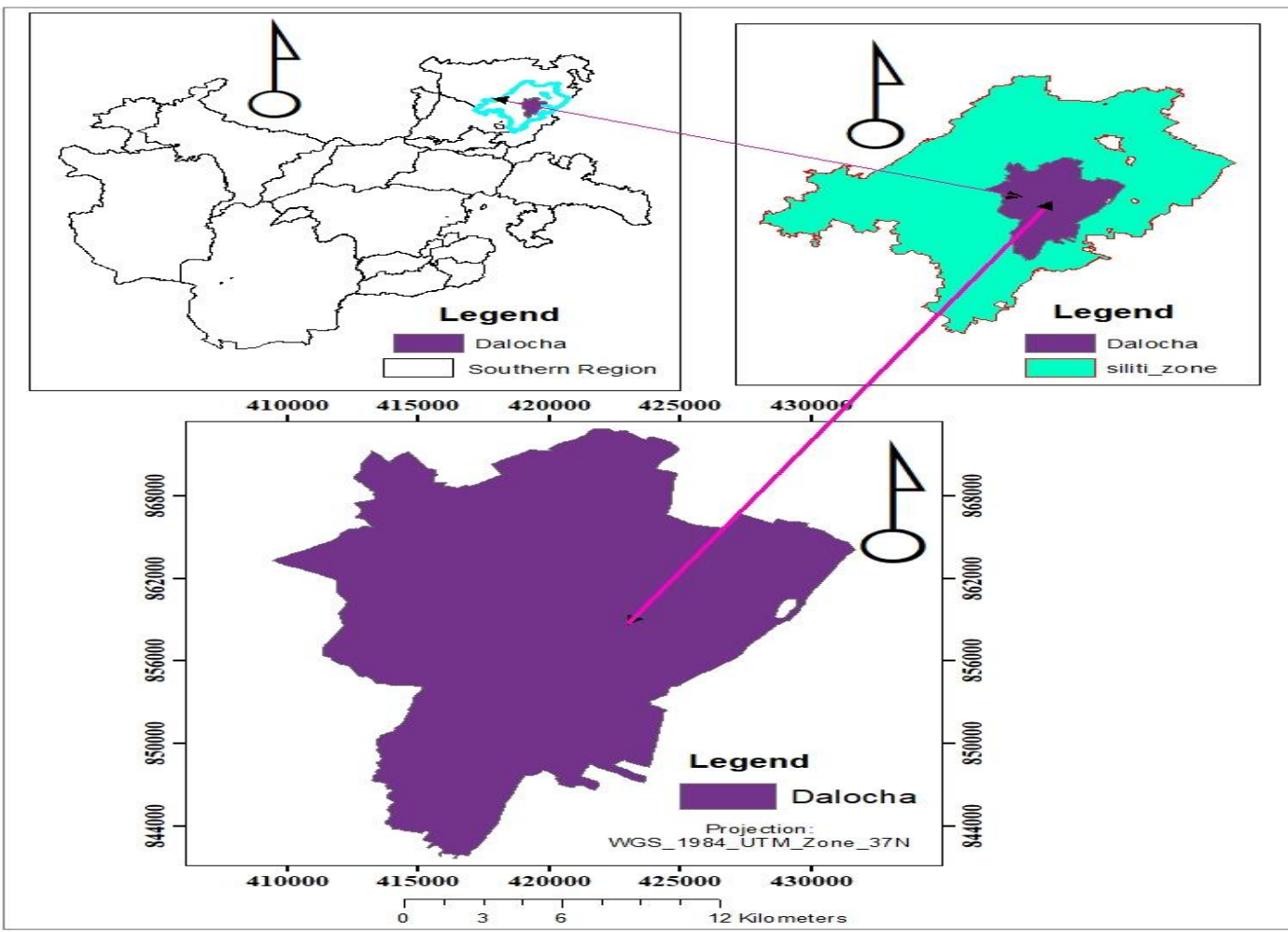

Figure 1. Dalocha woreda location map.

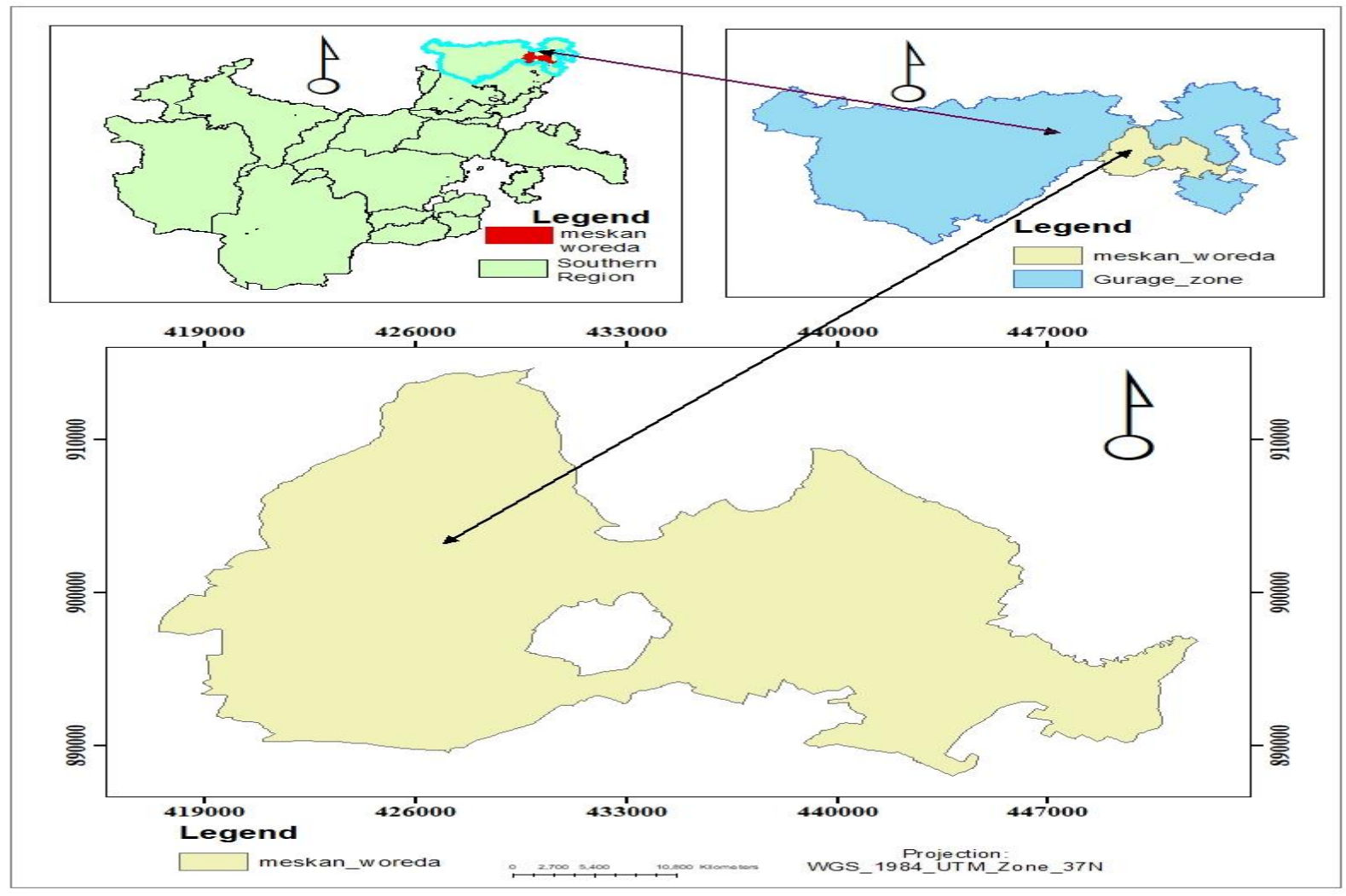

Figure 2. Meskan Woreda location map.

\section{Breeding materials, experimental design and management}

A total of ten recently released bread wheat genotypes were collected and used for the experiment. 6 genotypes from Kulumsa Agricultural Research Center and 4 genotypes from Holleta Agricultural Research Center, Ethiopia (Table 1). 
Table 1. List of Tested Genotypes.

\begin{tabular}{lll}
\hline Varieties & Source Center & Year of release \\
ET-13A & Kulumsa & 2012 \\
Hidasse & Kulumsa & 2012 \\
Hulluka & Kulumsa & 2012 \\
Ogolcho & Kulumsa & 2012 \\
Shorima & Kulumsa & 2012 \\
Kakaba & Kulumsa & 2010 \\
Alidoro & Holleta & 2007 \\
Wetera & Holleta & 2007 \\
Digalu & Kulumsa & 2005 \\
Merero & Holleta & 2005 \\
\hline
\end{tabular}

The ten (10) bread wheat varieties were assigned in Randomized Complete Block Design (RCBD) with four replications. Each plot consisted of six rows spaced $20 \mathrm{~cm}$ and the plot area was $3 \mathrm{~m}^{2}(2.5 \mathrm{~m} \times 1.2 \mathrm{~m})$. A $1.5 \mathrm{~m}$ distance was maintained between replication and $50 \mathrm{~cm}$ between plots used for both sites. Fertilizers was applied at the rate of $150 \mathrm{~kg} / \mathrm{ha}$ urea and $100 \mathrm{~kg} / \mathrm{ha}$ Diammonium Phosphate (DAP) at the time of planting and tillering. Seeding was done at the rate of $125 \mathrm{Kg} / \mathrm{ha}$. Seed and fertilizer was drilled uniformly by hand. Weeding and other agronomic practice was carried out as per recommendations of the respective sites.

\section{Data collection method}

The major agronomic data: - Plant height, spike length, number of tillers, biomass, grain yield and other yield related traits were collected. Plant height, spike length and tillers per plants were collected from ten plants from the central four rows.

Plant height (PHT): The average height in $\mathrm{cm}$ from ground level to the tip of the spike.

Spike length (SL): The average spike length in $\mathrm{cm}$ from its base to the tip.

Tillers/plant (TPP): The average number of productive tillers per plants.

Biomass (BM): The plants within the four central rows were harvested and weighed in kilo grams.

Grain yield (GY): Grain yield in grams obtained from the central four rows of each plot and converted to kilograms per hectare.

Harvest index (HI): The ratio of grain yield measured to the biomass weight.

\section{Statistical analysis}

A significance test was adopted by analysis of variance (ANOVA) for Randomized Complete Block Design. The ANOVA was carried out using the General Linear Model of the SAS Version 9.4 procedure. For factors showing significant effects, mean comparisons were made using Least Significance Difference (LSD) at $5 \%$ level of significance.

\section{Results and Discussion}

\section{Growth and yield related traits}

The tested bread wheat genotypes showed significance difference $(P<0.01)$ in collected parameters over the two locations (Table 2). The average plant height of variety ranged from 75.5 to $90.3 \mathrm{~cm}$. On similar studies Kifle Zerga et al, (2017) reported plant height range of 54.7 to $82.57 \mathrm{~cm}$ on wheat genotypes. In the present study the tallest plants were measured from Digalu variety with $90.3 \mathrm{~cm}$ and the shortest plant height were recorded $75.5 \mathrm{~cm}$ from Kakaba variety. The tested varieties considerably vary on the spike length which has positive contribution for yield increment. The average spike length ranges from 6.2 to $8.8 \mathrm{~cm}$. Hidasse recorded the tallest spike length with $8.8 \mathrm{~cm}$ while Digalu variety recorded the shortest length of $6.2 \mathrm{~cm}$. Spike length has strong positive correlation with grain yield with correlation coefficient of 0.67 (Table 3 ). The number of productive tillers per plant indicated a high significance difference $(P<0.01)$ among tested varieties. The average number of productive tiller ranges from 2.6 to 3 . Kakaba and Hidasse varities ranked first on the number of productive tillers with 3 while the least number of tillers (2.6) were recorded from Merero and ET-13A varieties. Related range and mean was reported from the finding of Obsa (2014). The number of productive tillers has strong positive correlation with grain yield with correlation coefficient of 0.6 (Table 3). There was significant variation in the value of above ground biomass among varieties. The value of above ground biomass range from 9666.7 to $11333.3 \mathrm{~kg} / \mathrm{ha}$. On similar study Kifle Zerga et al, (2017) reported maximum above ground biomass of $10491.7 \mathrm{~kg} / \mathrm{ha}$. The highest biomass recorded in the present study was $11333.3 \mathrm{~kg} / \mathrm{ha}$ from variety Alidoro and the lowest biomass recorded was $9666.7 \mathrm{~kg} / \mathrm{ha}$ from Digalu variety. The analysis of variance showed that there were significant $(P<0.01)$ differences among bread wheat varieties in yield of dry seed (Table 2). The total grain yield recorded for most of the varieties in the study was lower than the national average yield of bread wheat; which could be due the occurrences of stem rust and erratic rainfall during the growing season. The yield of the genotype ranged from 3220 to $5210 \mathrm{~kg} / \mathrm{ha}$. In this study Hidasse and Ogolcho variety recorded 5210 and $5080 \mathrm{~kg} / \mathrm{ha}$ respectively which is the highest yield recorded. Related yield range was reported by Adhiena Mesele (2015). However Digalu and Merrero produced the lowest yield with 3220 and $4170 \mathrm{~kg} / \mathrm{ha}$ respectively.

Table 2. The mean performance of agronomic characters for the tested wheat genotypes.

\begin{tabular}{lllllll}
\hline Genotypes & PHT(cm) & SL(cm) & TPP & BM(kg/ha) & GY(kg/ha) & HI \\
Alidoro & 89.4 & 8.6 & 2.8 & 11333.3 & 4930 & 0.4 \\
Digalu & 90.3 & 6.2 & 2.7 & 9666.7 & 3220 & 0.3 \\
\hline \hline
\end{tabular}




\begin{tabular}{lllllll}
\hline ET-13A & 82.8 & 7.5 & 2.6 & 11000.0 & 4830 & 0.4 \\
Hidasse & 76.2 & 8.8 & 3 & 11000.0 & 5210 & 0.5 \\
Huluka & 83.2 & 7.6 & 2.8 & 11000.0 & 4810 & 0.4 \\
Kakaba & 75.5 & 7 & 3 & 10000.0 & 4580 & 0.5 \\
Merero & 76.3 & 7.2 & 2.6 & 10000.0 & 4170 & 0.4 \\
Ogolcho & 77.4 & 8.6 & 2.8 & 10333.3 & 5080 & 0.5 \\
Shorima & 77.8 & 7.2 & 2.7 & 10000.0 & 4350 & 0.4 \\
Wetera & 79.1 & 6.8 & 2.9 & 10333.3 & 4730 & 0.5 \\
LSD(0.05) & 3.8 & 0.5 & 0.2 & 954.3 & 457.1 & 0.04 \\
CV \% & 4.7 & 6.7 & 8.4 & 9.1 & 10 & 10.8 \\
\hline
\end{tabular}

Key: $\mathrm{PHT}=$ Plant Height, $\mathrm{SL}=$ Spike Length, TPP=Tillers Per Plant, BM=Biomass, GY=Grain Yield, HI=Harvest Index, LSD=Least Significant Difference, and CV=Coefficient of Variation.

Table 3. Correlations among traits.

\begin{tabular}{lllllll}
\hline & PH & SL & TPP & BM & GY & HI \\
PH & & & & & \\
SL & 0.26 & & & & \\
TPP & -0.21 & $0.49 *$ & & & \\
BM & 0.20 & 0.38 & 0.15 & $0.74 * *$ & \\
GY & 0.18 & $0.67 * *$ & $0.60 * *$ & $0.69 * *$ & \\
HI & 0.35 & 0.25 & 0.16 & 0.2 & 0.25, GY \\
\hline
\end{tabular}

Key: $\mathrm{PHT}=$ Plant height, $\mathrm{SL}=$ Spike length, TPP=Tillers per plant, BM=biomasS, GY=Grain yield, HI=Harvest index, LSD=least significant difference, and $\mathrm{CV}=$ coefficient of variation

* Correlation is significant at 0.05 level.

** Correlation is significant at 0.01 level.

\section{Conclusion and Recommendations}

Shortage of improved varieties, which are well adapted through trial in the study area to the farmers was one of the main problems. This study generally indicated that there is an opportunity in selection of superior genotypes among tested bread wheat genotypes through direct selection at the study locations as short term strategy rather than a lengthy crossing program.

It was found that there is $38.19 \%$ boost of yield for using Hidasse genotype (high yielder) as compared to Digalu genotype (low yielder) at the study area. Variety, Hidasse and Ogolcho were well performed at both locations. These varieties can be used for wheat production and seed system program at both locations.

\section{Acknowledgements}

We are grateful to farmers of the study zones who made this variety evaluation study possible. The Bureau of Agriculture staffs at zone and district levels, development agents, and the Worabe Research centre are greatly acknowledged for facilitation of the work. Thanks also go to the South Agricultural Research Institute for funding this research.

\section{References}

Abu, T, (2012). Grain and feed annual report. Grain report number: ET1201, Addis Ababa, Ethiopia ( Triticum aestivum L.). Research in Plant Biology, 3(1): 33-36.

Adhiena, M. (2015). Genetic variability and association among seed yield and yield related traits in bread wheat (Triticum aestivum L.) Genotypes at Ofla District, Northern Ethiopia. M.Sc. Thesis, Haramaya University, Haramaya, Ethiopia

CSA (Central Statistics Authority) (2013). Report on area and crop production forecast for major grain crops. Addis Ababa, Ethiopia: Statistical Bulletin.

FAO (2015). Food and agricultural organization of the united nations, Rome, Italy.

Kifle Zerga, Firew Mekbib, Tadesse Dessalegn (2017). The Mean Performance of Different Bread Wheat (Triticum aestivum. L) Genotypes in Gurage Zone, Ethiopia. Landscape Architecture and Regional Planning, 2 (1): 29-35.

Mollasadeghi, V., Shahryari, R. (2011). Important morphological markers for improvement of yield in bread wheat. Advances Environmental Biology, 5 (3): 538-542.

Obsa (2014). Genetic variability among bread wheat (Triticum aestivum L.) genotypes for growth characters yield and yield components in Bore district, Oromia regional state M.Sc. Thesis, Haramaya University, Haramaya, Ethiopia.

\section{Citation:}

Shibeshi, S. (2019 Performance evaluation of released bread wheat varieties at mid altitude areas of southern Ethiopia. Ukrainian Journal of Ecology, 9(4), 661-664. 